\title{
Flow-based stereoselective reduction of ketones using an immobilized ketoreductase/glucose dehydrogenase mixed bed system
}

\author{
Federica Dall'Oglio $^{\text {a }}$, Martina Letizia Contente ${ }^{\mathrm{b}}$, Paola Conti ${ }^{\mathrm{a}}$, Francesco Molinari ${ }^{\mathrm{b}}$, Danila Monfredi ${ }^{\mathrm{b}}$, Andrea \\ Pinto $^{\text {a }}$, Diego Romano ${ }^{\text {b }}$, Daniela Ubiali ${ }^{\text {, }}$, Lucia Tamborini ${ }^{\text {a, }}$, Immacolata Serra ${ }^{\text {b,* }}$ \\ ${ }^{a}$ Department of Pharmaceutical Sciences (DISFARM), University of Milan, Via Mangiagalli 25, 20133 Milano, Italy \\ ${ }^{b}$ Department of Food, Environmental and Nutritional Sciences (DeFENS), University of Milan, Via Mangiagalli 25, 20133 Milano, Italy \\ ${ }^{c}$ Department of Drug Sciences, University of Pavia, Viale Taramelli 12, 27100 Pavia, Italy
}

\begin{abstract}
A robust two-enzyme system composed of an immobilized ketoreductase (KRED1-Pglu) and a glucose dehydrogenase $(\mathrm{Bm} \mathrm{GDH})$ was developed via immobilization on aldehyde agarose for the stereoselective reduction of different ketones. The immobilized ketoreductase/glucose dehydrogenase system was continuously used in a flow reactor for weeks, even in the presence of concentrations of DMSO up to $20 \%$.
\end{abstract}

Keywords: biocatalysis $\bullet$ ketoreductase $\bullet$ enantioselective reduction $\bullet$ flow reactor $\bullet$ immobilization

\section{Introduction}

Biocatalytic processes can be improved with the use of different and complementary strategies, including protein or metabolic engineering and immobilization techniques [1]. Besides, biocatalysis in flow chemistry reactors, where rates and productivities can be largely enhanced, seems a logical option [2]. Flow-based applications have potential advantages, such as: increased mixing efficiency, controlled scaling factors, improved safety ratings, in-line control and product recovery, easy set-up of cascade reactions, and continuous processing capabilities [3-5].

Flow-based biocatalysis has recently attracted interest for screening, optimizing or setting up preparative biotransformations $[6,7]$. Biotransformations such as hydrolysis and formation of esters [8-12], formation of C-C bonds using transketolases [13], preparation of monosaccharides [14] and oligosaccharides [15], synthesis of nucleosides [16], interconversion of carbonyls and amines using transaminases [17, 18], and peptide condensation [19] have been reported in the last few years. Stereoselective enzymatic carbonyl reduction with immobilized systems has been poorly investigated [20-23] and, to our knowledge, only one example has been reported using an immobilized ketoreductase in a plug flow reactor [24]. Here we report the use of a mixed bed system composed of immobilized ketoreductase from Pichia glucozyma (KRED1-Pglu) [25, 26] and a glucose dehydrogenase from Bacillus megaterium (Bm $\mathrm{GDH})$ [27] for the stereoselective reduction of ketones in a flow reactor.

\section{Experimental}

\subsection{General procedure for batch biotransformations}


Reactions were carried in $2 \mathrm{~mL}$ volume of $50 \mathrm{mM}$ Tris $\mathrm{HCl}$ buffer $\mathrm{pH} 8.0$ containing NADP ${ }^{+}(0.1 \mathrm{mM})$, substrate $(0.5 \mathrm{~g} / \mathrm{L})$, glucose ( 4 eq $\times$ eq of substrate) at $30^{\circ} \mathrm{C}$. The reaction was started by the addition of KRED1-Pglu and $B m \mathrm{GDH}$, maintained under orbital shaking (180 rpm), and was monitored by HPLC.

\subsection{General procedure for flow biotransformations}

Solutions of the substrates at different concentrations were prepared in Tris $\mathrm{HCl}$ buffer $\mathrm{pH} 8.0(50 \mathrm{mM})$ with DMSO (variable percentages depending on the substrate, for details see Table 2), $0.1 \mathrm{mM} \mathrm{NADP}^{+}$and glucose ( $4 \mathrm{eq} \times$ eq of substrate). An Omnifit glass column (6.6 mm i.d. x $100 \mathrm{~mm}$ ) was packed with pre-mixed KRED1-Pglu (540 mg) and BmGDH (540 mg), in order to obtain a KRED1-Pglu $/ B m$ GDH ratio of $1 / 25$. The volume of the reactor was $0.90 \mathrm{~mL}$. The packed column was prewashed by flowing through it a solution of Tris $\mathrm{HCl}$ buffer $\mathrm{pH} 8.0(0.050 \mathrm{~mL} / \mathrm{min}$ for 15 minutes $)$ followed by a solution of Tris $\mathrm{HCl}$ buffer $\mathrm{pH} 8.0$ with DMSO $(0.050 \mathrm{~mL} / \mathrm{min}$ for 15 minutes). Then, the substrate solution was pumped through the column maintained at $30^{\circ} \mathrm{C}$. The exiting solution was collected and analyzed at different times.

See Supplementary Materials for other experimental details.

\section{Results and Discussion}

Ketoreductase from Pichia glucozyma (KRED1-Pglu) and glucose dehydrogenase from Bacillus megaterium (BmGDH) were prepared as previously reported [26, 27] (see Supplementary Materials for details). The first support taken into account was the commercially available epoxy-activated Relizyme 403/S. Although KRED1-Pglu was completely bound to the support, the resulting biocatalyst was poorly active ( $4 \%$ of expressed activity). Moreover, on the same support only $2 \%$ of the offered $B m \mathrm{GDH}$ was bound to the matrix. Aldehyde activated agarose, a support suitable for the immobilization/stabilization of several enzymes [28, 29], including ketoreductases, was alternatively employed for immobilization. Immobilization on aldehyde agarose relies on the reaction between not protonated $\varepsilon$-amino groups of surface lysines and aldehyde groups on the support. Since alkaline conditions $(\mathrm{pH} \geq 10)$ are required to ensure that the $\varepsilon$-amino groups are not protonated, stability studies of both soluble enzymes were carried out at this $\mathrm{pH}$. $\mathrm{BmGDH}$ lost more than $50 \%$ of the initial activity after 1 hour of incubation at $\mathrm{pH} 10.0$ both at 25 and $4{ }^{\circ} \mathrm{C}$. The addition of stabilizing agents (glycerol or PEG600) allowed to maintain 100\% and $70 \%$ of the initial activity after 3 hours of incubation at $\mathrm{pH} 10$ [30,31]. On the other side, KRED1-Pglu retained $100 \%$ of its initial activity over 3 hours at $\mathrm{pH} 10.0$ under all the conditions tested $\left(25^{\circ} \mathrm{C}\right.$ or $4{ }^{\circ} \mathrm{C}$ with $20 \%$ glycerol as additive). On the basis of these stability tests, immobilization of KRED1-PGlu was assayed under different conditions. The best results for the immobilization of KRED1-PGlu were obtained at $4{ }^{\circ} \mathrm{C}$ without additives and independently from protein loading (Table 1, entry 1 and 3). For $B m \mathrm{GHD}$, as a consequence of the stability requirements, it was necessary to add stabilizing additives to the immobilization mixture. The addition of $20 \%$ of glycerol allowed to retain $32 \%$ and $28 \%$ of activity upon immobilization at $25{ }^{\circ} \mathrm{C}$ (Table 1, entry 7 and 9) while the addition of PEG600 was not beneficial to the immobilization outcome (Table 1, entry 8 and 10$)$.

Table 1. Immobilization of KRED1-PGlu and $B m G D H .{ }^{a}$

\begin{tabular}{ccccccc}
\hline Entry & Enzyme & Load $\left(\mathrm{mg} \mathrm{g}^{-1}\right)$ & ${\mathrm{T}\left({ }^{\circ} \mathrm{C}\right)}$ & Additive & Immobilized protein $(\%)^{\mathrm{b}}$ & Yield $(\%)$ \\
\hline $\mathbf{1}$ & KRED1-PGlu & 7 & 4 & - & 98 & $40^{\mathrm{c}}$
\end{tabular}




$\begin{array}{ccccccc}\mathbf{2} & \text { KRED1-PGlu } & 7 & 25 & - & 97 & 14^{\mathrm{c}} \\ \mathbf{3} & \text { KRED1-PGlu } & 14 & 4 & - & 98 & 40^{\mathrm{c}} \\ \mathbf{4} & \text { KRED1-PGlu } & 14 & 25 & - & 92 & 12^{\mathrm{c}} \\ \mathbf{5} & \text { KRED1-PGlu } & 7 & 25 & 20 \% \text { glycerol } & 99 & 12^{\mathrm{c}} \\ \mathbf{6} & \text { KRED1-PGlu } & 14 & 25 & 20 \% \text { glycerol } & 97 & 9^{\mathrm{c}} \\ \mathbf{7} & \text { BmGDH } & 5 & 25 & 20 \% \text { glycerol } & 92 & 32^{\mathrm{d}} \\ \mathbf{8} & \text { BmGDH } & 5 & 25 & 20 \% \text { PEG600 } & 87 & 5^{\mathrm{d}} \\ \mathbf{9} & B m \mathrm{GDH} & 10 & 25 & 20 \% \text { glycerol } & 90 & 28^{\mathrm{d}} \\ \mathbf{1 0} & B m \mathrm{GDH} & 10 & 25 & 20 \% \text { PEG600 } & 84 & 5^{\text {d }}\end{array}$

[a] Experimental conditions: $\mathrm{pH}$ 10.0, 3 h. [b] Determined by Bradford method. [c] Determined by comparison of the loaded and recovered activity towards 4'-nitroacetophenone (1a) [32]. [d] Determined by comparison of the loaded and recovered activity assayed towards glucose.

The stability of the free and immobilized enzymes was compared at $30^{\circ} \mathrm{C}$ in the presence of different concentrations of DMSO (Fig. S1 and S2), a water-soluble solvent often employed for solubilizing hydrophobic substrates in biocatalytic reactions. Immobilization remarkably improved the enzymatic stability towards DMSO: 60-65\% residual activity was found for immobilized KRED1-Pglu after 24 hours in the presence of 5-20\% DMSO, and only 4-6\% of the original activity was lost in the case of immobilized $\mathrm{BmGDH}$. It should be noted that both the free enzymes were mostly inactivated after 6 hours even at the lowest DMSO concentration (Fig. S1A and S2A).

The two immobilized proteins were blended together to obtain a homogeneous agarose gel system suited for catalyzing the stereoselective reduction of ketones at $30^{\circ} \mathrm{C}$ with an efficient regeneration system for NADPH/NADP ${ }^{+}$. This system was able to convert 4-nitroacetophenone 1a with yields between $78-83 \%$ in the presence of DMSO ranging from 4 to $8 \%$ while lower yields were observed at higher co-solvent concentrations (Figure 1); 2 a was always recovered with an ee $>98 \%$. Sluggish reactions could be observed with free enzymes in the presence of DMSO concentrations above 4\%. Compound 1a is mostly insoluble in water at $30^{\circ} \mathrm{C}$, while it is largely soluble in aqueous solutions with DMSO concentrations above $4 \%$. 


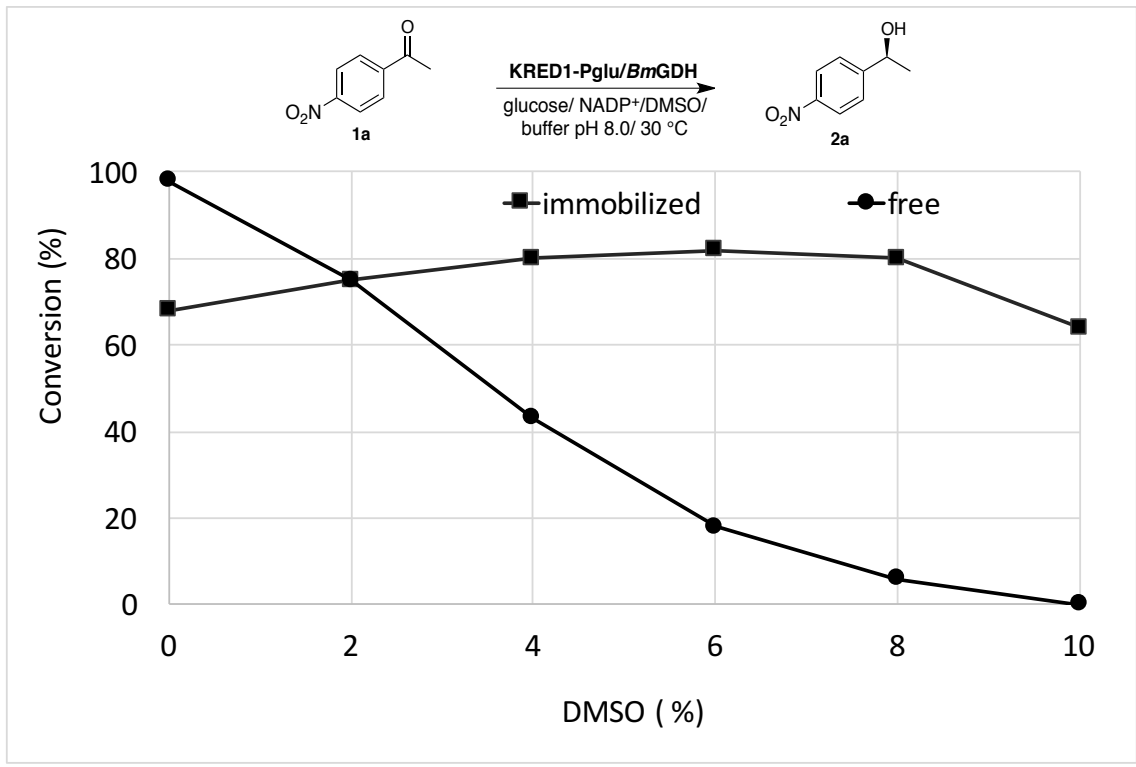

Fig. 1. Reduction of 1a into 2a by free and immobilized KRED1-Pglu/BmGDH in the presence of different concentrations of DMSO (batch reactions).

The re-usability of the immobilized system was investigated in a sequence of reaction cycles performed in the presence of 5\% DMSO, where the biocatalysts were recovered by filtration after every cycle and used for a new batch reaction. The immobilized biocatalysts lost $20 \%$ of the original activity after one cycle and were totally inactive after 4 reaction cycles (see Fig. S3).

The reduction of 1a was then carried out with the immobilized enzymes in a continuous packed bed flow reactor. Different amounts of the immobilized enzymes were mixed to find the best KRED1-Pglu/BmGDH ratio (see Fig. S4). The best results ( $>97 \%$ conversion with a residence time of $180 \mathrm{~min}$ ) were obtained using a KRED1-Pglu/BmGDH ratio of 1/25, corresponding to $55 \mathrm{mU}$ for KRED1-Pglu (100 mU/g), and $1375 \mathrm{mU}$ for $B m \mathrm{GDH}(2750 \mathrm{mU} / \mathrm{g})$.

The continuous flow reaction was carried out for 15 days in the presence of 5\% DMSO with no significant change of the chemical composition of the outflow solution, which contained $97-98 \%$ of optically pure (S)-1-(4-nitrophenyl)ethanol (2a) (Fig. 2). Noteworthy, after 6 months of operation, the flow reactor only lost 30-32\% of the original activity. The different operational stability shown by the immobilized system in the flow reactor and in shaken flasks may be due to the reduced mechanical stress under flow conditions. It should be underlined that biotransformations with immobilised enzymes are multiphase systems needing continuous agitation in conventional batch reactors, agitation (orbital shaking in our case) can damage or grind the biocatalyst to fine particles [33]. 


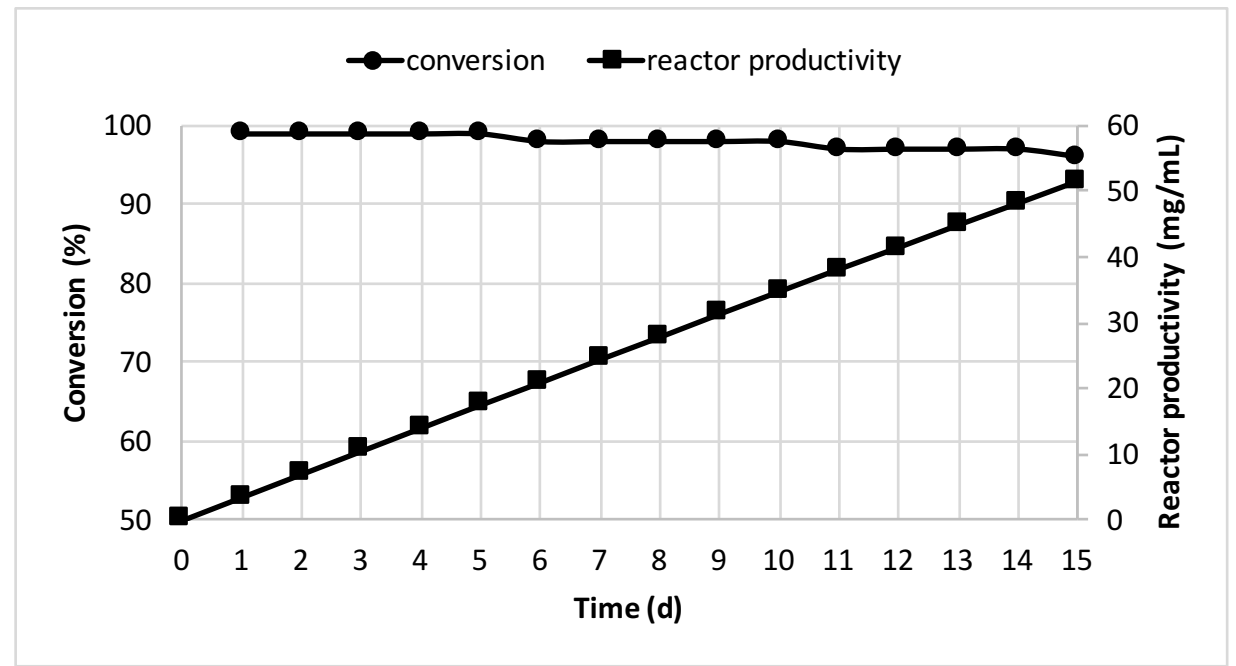

Fig. 2. Continuous reduction of $1 \mathrm{a}$ in flow reactor.

The flow reaction was also applied to the stereoselective reduction of other ketones (1)-1d). These substrates have a different solubility in water: compounds $\mathbf{1 b}$ and $\mathbf{1 c}$ are mostly soluble in 10\% DMSO aqueous solutions, whereas ethyl secodione $\mathbf{1 d}$, a key intermediate for the synthesis of a number of hormonal contraceptives [34, 35], is soluble only at $20 \%$ DMSO concentration. Flow reactions were carried out by pumping aqueous-DMSO solutions containing the substrate (3.0 mM), $\mathrm{NADP}^{+}(0.1 \mathrm{mM})$, and glucose $(12.0 \mathrm{mM})$ through the packed bed reactor. The highest yield was achieved at relatively low residence times (Table 2). 1-Phenylpropane-1,2-dione $\mathbf{1 b}(3 \mathrm{mM})$ gave optically pure $(S)$-2-hydroxy-1-phenylpropan-1-one (Table 2, entry 1) with a total conversion in correspondence of a very low residence time ( $7 \mathrm{~min}$ ); the same reaction catalysed by the free enzymes in batch mode gave a total conversion of the substrate ( $3 \mathrm{mM})$ in 60 min. 1-Phenylbutane-1,3-dione 1c was reduced to $(S)$-3-hydroxy-1-phenylbutan-1-one $\mathbf{2 c}$ by the free enzymes in pure aqueous solution with a maximum yield of $60 \%$ (ee $>98 \%$ ) after 24 hours; the reduction in flow by immobilized enzymes and 10\% DMSO allowed for a very high yield $(95 \%)$ with a residence time of $120 \mathrm{~min}$ (Table 2, entry 2). A less pronounced improvement of the productivity was observed for the enantioselective reduction of the highly water-insoluble secodione 1d. In fact, the reaction of 1d with the free enzymes in batch gave yields up to $65 \%$ after 8 hours starting from $6.5 \mathrm{mM}$ substrate concentration, under conditions where the substrate was largely insoluble [35]; when the bioconversion was transferred in the flow mode, it was necessary to use a flow stream containing lower substrate concentration (3 mM) and relatively high DMSO concentrations (20\%) to have a homogeneous system. Under these conditions, yields of $65 \%$ were reached with a residence time of 180 min (Table 2 , entry 3).

Table 2. Continuous stereoselective reduction of diketones 1b-1d (3 mM) with immobilized KRED1-Pglu/BmGDH in flow reactor. ${ }^{\text {a }}$ 


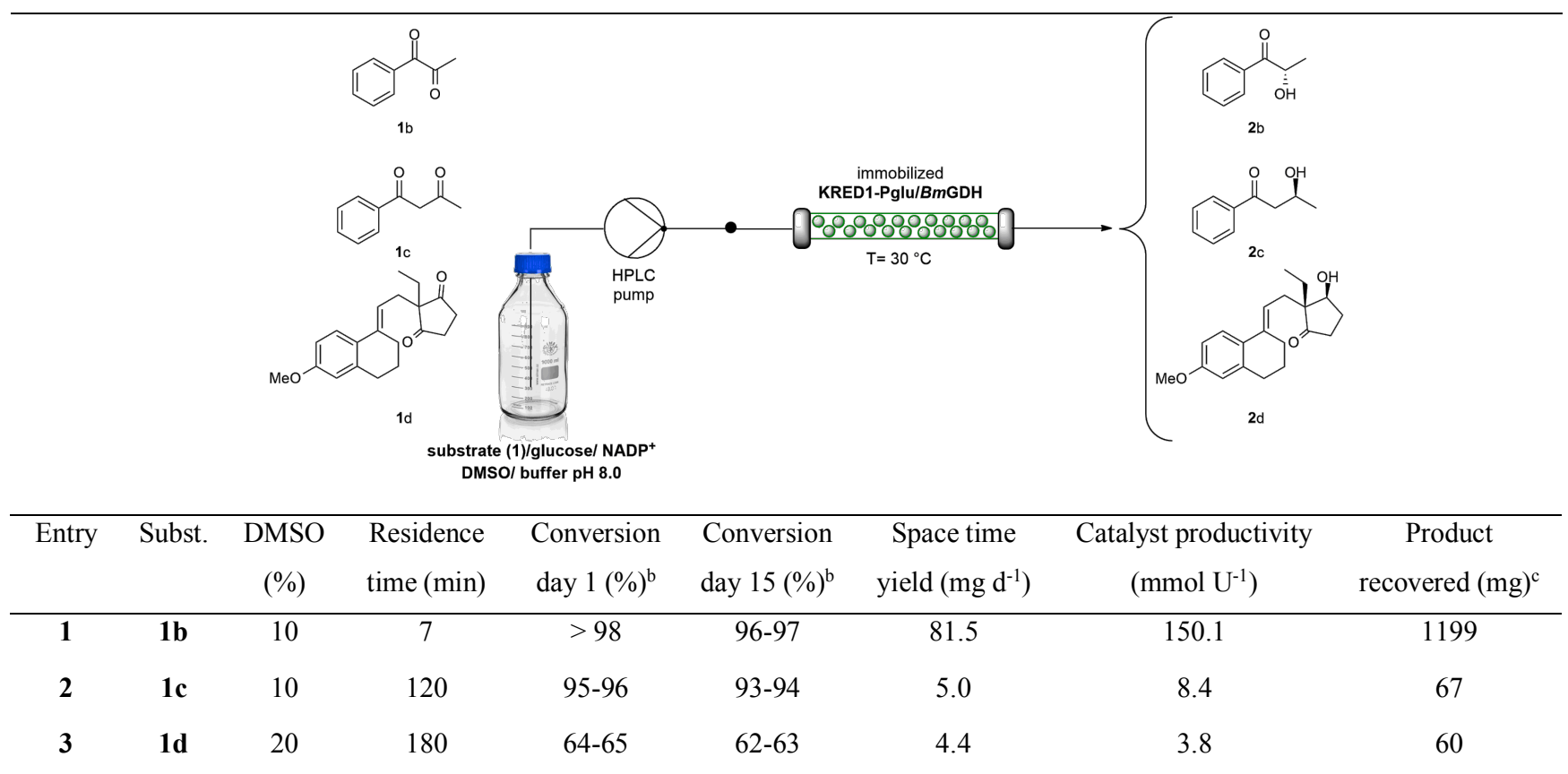

[a] Flow solutions contained [1b-d] $3.0 \mathrm{mM}$, NADP $\left.^{+}\right] 0.1 \mathrm{mM}$, [glucose] $12.0 \mathrm{mM}$ in Tris HCl buffer pH $8.0(50 \mathrm{mM})$ in the presence of different amounts of DMSO. [b] Determined by HPLC. [c] After purification by flash chromatography.

The flow biotransformation of ketones 1b-1d was carried out in a continuous mode without significant changes of the composition of the outflow stream for 15 days; details about the continuous reaction in the flow reactor of the three substrates (residence times, conversions, stability, enantiomeric excesses, space time yields, and isolated yields) are given in Table 2. The stability of the biocatalysts under these conditions enabled the obtainment of millimolar amounts of the desired products in a $0.90 \mathrm{~mL}$ reactor, using the same amount of enzyme that produced only micromolar quantities in batch reactions.

In conclusion, an immobilized system composed of a ketoreductase (KRED1-Pglu) and a glucose dehydrogenase (BmGDH) was successfully used to perform the continuous stereoselective reduction of ketones in a flow reactor for weeks; the prolonged operational stability in the flow reactor makes the set-up of the biotransformation attractive for preparative (bio)catalysis.

\section{Acknowledgements}

The authors wish to thank Cariplo Foundation for funding the project "INnovative Biocatalytic OXidations - INBOX" (Rif. 2014-0568). The financial support to the present research by the University of Milan (Piano di Sostegno alla Ricerca 2015/2017-Linea 2A) is also acknowledged.

\section{References}

[1] J.M. Choi, S.S. Han, H.S. Kim, Biotechnol. Adv. 33 (2015) 1443-1454.

[2] G. Gasparini, I. Archer, E. Jones, R. Ashe, Org. Process Res. Dev. 16 (2012) 1013-1016.

[3] C. Wiles, P. Watts, Green Chem. 14 (2012) 38-54.

[4] J. C. Pastre, D. L. Browne, S. V. Ley, Chem. Soc. Rev. 42 (2013) 8849-8869.

[5] B. Gutmann, D. Cantillo, C.O. Kappe, Angew. Chem. Int. Ed., 54 (2015) 6688-6728.

[6] J.M. Bolivar, J. Wiesbauer, B. Nidetzky, Trends Biotechnol. 29 (2011) 333-342.

[7] L. Hajba, A. Guttman, J. Flow Chem. 6 (2016) 8-12.

[8] I.I. Junior, M.C. Flores, F.K. Sutili, S.G.F. Leite, L.S. de M. Miranda, I.C.R. Leal, R.O.M.A. de Souza, Org. Process Res. Dev. 16 (2012) $1098-1101$. 
[9] L. Tamborini, D. Romano, A. Pinto, A. Bertolani, F. Molinari and P. Conti, J. Mol. Catal. B Enzym. 84 (2012) 78-82.

[10] I. Itabaiana, L.S. de M. Miranda, R.O.M.A. De Souza, J. Mol. Catal. B: Enzym. 85-86 (2013) 1-9.

[11] L. Tamborini, D. Romano, A. Pinto, M. Contente, M. C. Iannuzzi, P. Conti, F. Molinari, Tetrahedron Lett. 54 (2013) $6090-6093$.

[12] S.S. Wang, Z. J. Li, S. Sheng, F, A Wu, J. Wang, J. Chem. Technol. Biotechnol. 91 (2016) 555-562.

[13] J. Lawrence, B. O’Sullivan, G.J. Lye, R. Wohlgemuth, N. Szita, J. Mol. Catal. B Enzym. 95 (2013) 111-117.

[14] L. Babich, A.F. Hartog, L.J.C. van Hemert, F.P.J.T. Rutjes, R. Wever, ChemSusChem 5 (2012) 2348-2353.

[15] P. Zambelli, L. Tamborini, S. Cazzamalli, A. Pinto, S, Arioli, S. Balzaretti, F.J. Plou, L. Fernandez-Arrojo, F. Molinari, P. Conti, D. Romano, Food Chem. 190 (2016) 607-613.

[16] E. Calleri, G. Cattaneo, M. Rabuffetti, I. Serra, T. Bavaro, G. Massolini, G. Speranza, D. Ubiali, Adv. Synth. Catal. 357 (2015) $2520-2528$.

[17] L.H. Andrade, W. Kroutil, T.F. Jamison Org. Lett. 16 (2014) 6092-6095.

[18] M. Planchestainer, M.L. Contente, J. Cassidy, F. Molinari, L. Tamborini, F. Paradisi, Green Chem. (2017) DOI:10.1039/c6gc01780k.

[19] P. Falus, L. Cerioli, G. Bajnoczi, Z. Boros, D. Weiser, J. Nagy, D. Tessaro, S. Servi, L. Poppe, Adv. Synth. Catal. 358 (2016) $1608-1617$.

[20] D.H. Chen, M.H. Liao, Biotechnol. Lett. 23 (2001) 1723-1727.

[21] D. Metrangolo-Ruiz De Temino, W. Hartmeier, M.B. Ansorge-Schumacher, Enzyme Microb. Technol. 36 (2005) 3-9.

[22] H.M.S. Milagre, C.D.F. Milagre, P.J.S. Moran, M.H.A. Santana, J.A.R. Rodrigues, Org. Process Res. Dev. 10 (2006) 611-617.

[23] K. Nagayama, A.C. Spiess, J. Buchs, J. Biochem. Eng. J. 52 (2010) 301-303.

[24] H. Li, J. Moncecchi, M.D. Truppo, Org. Process Res. Dev. 19 (2015) 695-700.

[25] M.C. Fragnelli, P. Hoyos, D. Romano, R. Gandolfi, A.R. Alcántara, F. Molinari, F. Tetrahedron 68 (2012) 523-528.

[26] M.L. Contente, I. Serra, M. Brambilla, I. Eberini, E. Gianazza, V. De Vitis, F. Molinari, P. Zambelli, D. Romano, Appl. Microbiol. Biotechnol. 100 (2016) 193-201.

[27] K. Yamamoto, G. Kurisu, M. Kusunoki, S. Tabata, I. Urabe, S. Osaki, J. Biochem. 129 (2001) 303-312.

[28] C. Mateo, J.M. Palomo, M. Fuentes, L. Betancor, V. Grazu, F. Lopez-Gallego, B.C.C. Pessela, A. Hidalgo, G. Fernandez-Lorente, R. FernandezLafuente, J.M. Guisan, Enzyme Microb.Technol. 39 (2006) 274-280.

[29] P. Zucca, R. Fernandez-Lafuente, E. Sanjust, Molecules 21 (2016) 1577-1602.

[30] I. Serra, D. Ubiali, J. Piskur, S. Christoffersen, E. S. Lewkowicz, A. M. Iribarren, A M. Albertini, M. Terreni, ChemPlusChem 78 (2013) 157-165.

[31] A. Fresco-Taboada, I. Serra, M. Arroyo, J. Fernández-Lucas, I. de la Mata, M. Terreni, Catal. Today 259 (2015) 197-204.

[32] M.L. Contente, I. Serra, L. Palazzolo, C. Parravicini, E. Gianazza, I. Eberini, A. Pinto, B. Guidi, F. Molinari, D. Romano, Org. Biomol. Chem. 14 (2016) 3404-3408.

[33] S. Cantone, V. Ferrario, L. Corici, C. Ebert, D. Fattor, P. Spizzo, L. Gardossi, Chem. Soc. Rev. 42 (2013) 6262-6276.

[34] A.S. Chapelon, D. Moraleda, R. Rodriguez, C. Ollivier, M. Santelli, Tetrahedron 63, (2007) 11511-11616.

[35] M.L. Contente, F. Molinari, I. Serra, A. Pinto, D. Romano, Eur. J. Org. Chem. (2016) 1260-1263. 